\title{
Analysis of factors delaying the surgical treatment of patients with neurological deficits in the course of spinal metastatic disease
}

\author{
Grzegorz Guzik
}

\begin{abstract}
Background: Thoracic spine cancer metastases is frequently the cause of neurological deficits. Despite the availability of diagnostics, delays in treatment are still quite common. The aim of this work is to analyze the reasons for delayed diagnostics and treatment, in patients with neurological deficits in the course of metastatic spine disease.

Methods: In our study patients medical data was analyzed from 2013 to 2015. The analysis covered the following aspects: symptoms of metastases, time of neurological deficits occurrence, where and when initial diagnostics were performed, time from diagnosis to proper surgical treatment in an oncological centre. In total, 411 patients were consulted and 287 were operated on. Of 112 patients with neurological deficits, 64 underwent surgeries. Women represented the majority of the patients. The most common primary neoplasms were breast cancer and myeloma.

Results: In $75 \%$ of the patients neurological symptoms occurred prior to admission to a hospital. The average time between the onset of neurological symptoms and medical consultation was 4 days. The patients were diagnosed mainly at neurologic, orthopedic and emergency departments. The mean time between undergoing radiological examinations and receiving the examinations results was 2.4 days for $C T$ and 2.8 days for MRI. The average time between a patients' admission from the department where they were initially diagnosed, to the orthopedic oncology ward was 4.5 days.
\end{abstract}

Conclusions: The most common cause of the delayed treatment of patients with neurological deficits, in the course of metastatic spine disease, is a combination of the lack of knowledge among patients and healthcare personnel regarding the necessity of early diagnosis.

Keywords: Metastases, Spinal tumors, Surgical treatment of the spine, Resections of spinal tumors, Spinal stabilization, Neurological deficits, Frankel scale

\section{Background}

The most common location for cancer metastases is the spine. The most frequently affected areas are the thoracic spine (70\%) followed by the lumbar spine (20\%), and lastly the cervical spine (10\%). $70 \%$ of thoracic metastases are associated with clear clinical symptoms and 5-15\% develop neurological deficits. Pain associated

Correspondence: grzegorz.guzik@vp.pl

Orthopedic Oncology Department, Specialist Hospital in Brzozów-

Podkarpacki Oncology Center, ul. Dworska 77a, 38-420 Korczyna, Polska, Poland

(c) The Author(s). 2018 Open Access This article is distributed under the terms of the Creative Commons Attribution 4.0 International License (http://creativecommons.org/licenses/by/4.0/), which permits unrestricted use, distribution, and reproduction in any medium, provided you give appropriate credit to the original author(s) and the source, provide a link to the Creative Commons license, and indicate if changes were made. The Creative Commons Public Domain Dedication waiver (http://creativecommons.org/publicdomain/zero/1.0/) applies to the data made available in this article, unless otherwise stated. 
and doctors to conduct early diagnostics, including CT and MR imaging. An early and thorough neurological assessment is also of importance [1,4-7].

The aim of this work was to analyze the reasons for delayed diagnostics and treatment of spine metastases causing neurological deficits.

\section{Methods}

In our study, patients data was analyzed from the years 2013-2014.

The time between the occurrence of neurological deficits and medical consultation was analyzed. The timeframe from the patients initial diagnosis, admission to the hospital and transfer to the proper spinal ward in an oncological centre, was analyzed. Contra-indications to surgical treatment were considered.

The inclusion criteria for the study was the occurrence of peripheral nervous system dysfunction in the course of histhopatologically confirmed metastatic disease of the spine. Undiagnosed patients, and patients with other diseases (tuberculosis, inflammation, primary neoplasm of the spine), were excluded from the study.

In total, 411 patients were consulted in our department, of which 344 were hospitalized and 287 were surgically treated. Of 411 patients, 112 of these presented neurological deficits. Neurological deficits were noted in 68 of 344 patients hospitalized in our ward and in 64 of 287 patients treated surgically. Figure 1 demonstrate examples of metastatic tumors of the spine, causing pathological fractures and spinal cord damage.

Women represented the majority of the patients, accounting for 255 cases (62\%). The median age was 63 years for women, and 68 years for men. The primary malignancies were cancer of the breast (127), myeloma (89), kidney (44), prostate (42), lymphoma (24), lung (21), colon (16), thyroid (11), gastric (8), and others (29) (Table 1).

The average time from the primary cancers diagnosis to spine metastases diagnosis was 11 months (range 254 months). Table 2 exhibits the mean duration from the diagnosis of metastatic disease, to the onset of neurological deficits.

Neurological assessment included the examination of muscle strength, sensation and tendon reflexes. The strength of muscles was evaluated using the Lovett scale (0- paralysis, 5- normal). Sensory examination included pain, touch, warm and cold feeling (0- loss of sensation, 2- normal sensation). Tendon reflexes examination evaluated the effectiveness of both the upper and lower limbs (0- absent reflex, 1- seen with reinforcement, 2normal, 3- very brisk, 4- clonus). Severity of neurological deficits was assessed according to the Frankel classification (A-complete impairment, E- normal). The findings of these examinations are presented in Table 3.
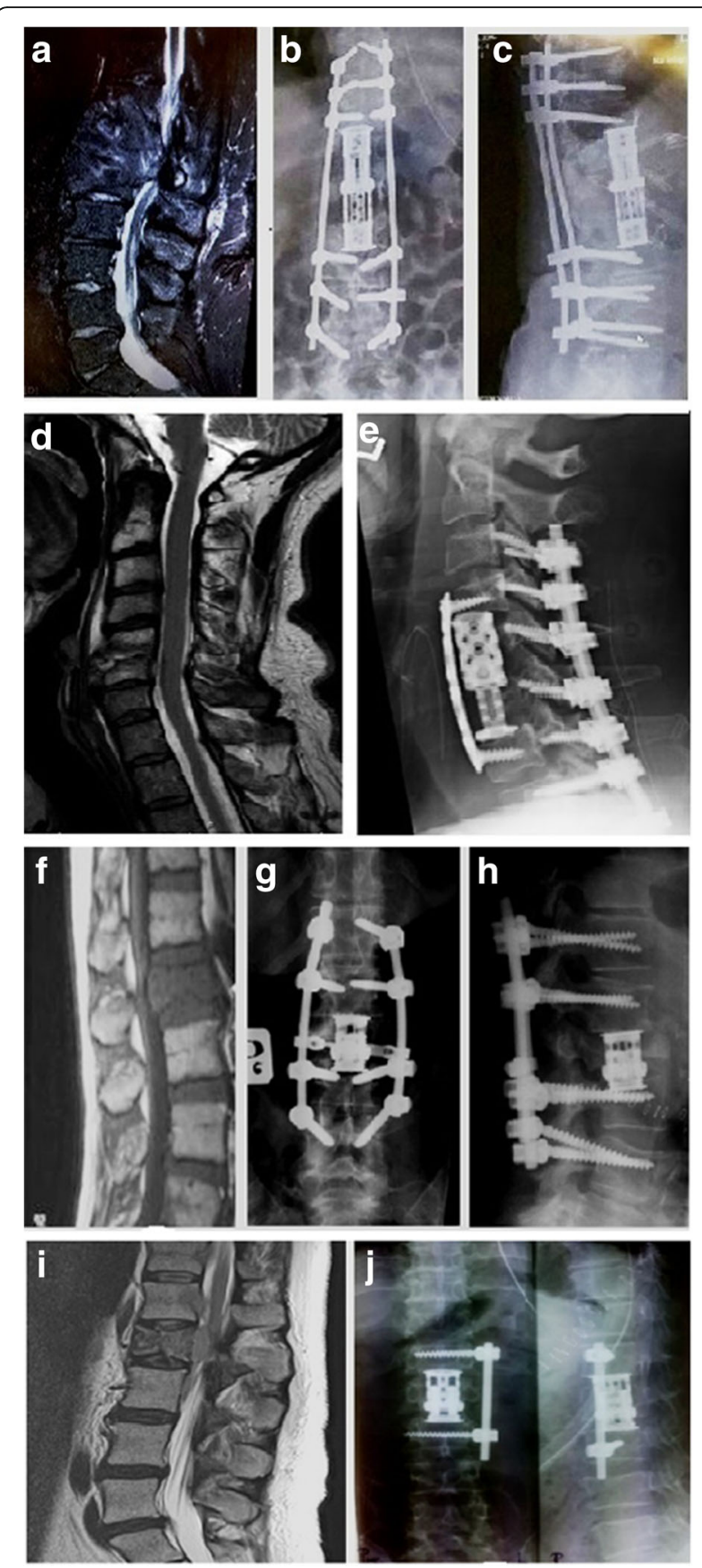

Fig. $1 \mathrm{MRI}$ image of metastatic thyroid cancer located in thoracic 11-12 and lumbar 1 vertebrae (a). Postoperative radiograms (b, c) showing vertebral prosthesis and posterior spine fixation. MRI images of C5-C6 breast cancer metastasis (d), and after tumor resection and cervical spine reconstruction (e). MRI image of metastatic breast cancer in the second lumbar vertebrae (f). Postoperative radiograms $(\mathbf{g}, \mathbf{h})$ after 360 degree reconstruction of the spinal column. MRI of fractured second lumbar vertebrae (i) and after prosthesis implantation and lateral spinal fixation (j)

Of 411 patients, 124 were disqualified from surgical treatment due to the following reasons: bad general condition (76 patients), no consent to surgical intervention 
Table 1 Number of patients with metastases to the spine and neurological deficits in relation to the type of neoplasm

\begin{tabular}{lll}
\hline Type of neoplasm & $\begin{array}{l}\text { Total number of patients } \\
\text { with metastases (411) }\end{array}$ & $\begin{array}{l}\text { Number of patients with } \\
\text { neurological deficits (112) }\end{array}$ \\
\hline Breast cancer & 127 & 38 \\
Myeloma & 89 & 26 \\
Kidney cancer & 44 & 12 \\
Prostate cancer & 42 & 13 \\
Lymphoma & 24 & 6 \\
Lung cancer & 21 & 4 \\
Colon cancer & 16 & 2 \\
Thyroid cancer & 11 & 2 \\
Gastric cancer & 8 & 2 \\
Others & 29 & 7 \\
\hline
\end{tabular}

(20 patients), tumor extensions (large multi-segmental lesions, extensive vascularisation, skin lesions at the surgical site) - (18 patients), age (10 patients). In a group of 112 patients with neurological deficits, 24 patients were disqualified from the treatment, due to poor general health (16 patients) and long-lasting paralysis, accompanied by poor prognosis and morphological changes of the spinal cord (8 patients).

\section{Results}

In the majority of the patients $(84,75 \%)$ neurological deficits prior to admission to the hospital were present. In 22 patients (20\%), the symptoms were diagnosed during a routine medical examination in the outpatient oncology clinics in our Hospital. In 6 patients (5\%) the onset of neurological deficits occurred suddenly, in the course of oncological treatment in our facility.

The patients who were conscious of the fact that their neurological status was worsening, visited their physicians

Table 2 The mean duration time from spine metastases discovery to neurological deficits occurrence

\begin{tabular}{ll}
\hline Type of neoplasm & $\begin{array}{l}\text { The mean duration time from metastatic } \\
\text { spine disease diagnosis to neurological } \\
\text { deficits occurrence (months) }\end{array}$ \\
\hline Breast cancer & 26 \\
Myeloma & 5 \\
Kidney cancer & 14 \\
Prostate cancer & 31 \\
Lymphoma & 7 \\
Lung cancer & 3 \\
Colon cancer & 21 \\
Thyroid cancer & 31 \\
Gastric cancer & 3 \\
Others & 6 \\
\hline
\end{tabular}

Table 3 Severity of neurological deterioration in relation to the type of primary neoplasm

\begin{tabular}{lllll}
\hline Type of neoplasm & Frankel A & Frankel B & Frankel C & Frankel D \\
\hline Breast cancer & 9 & 13 & 10 & 6 \\
Myeloma & 6 & 9 & 8 & 3 \\
Kidney cancer & 3 & 6 & 2 & 1 \\
Prostate cancer & 4 & 6 & 1 & 2 \\
Lymphoma & 3 & 2 & - & 1 \\
Lung cancer & 1 & - & 1 & 2 \\
Colon cancer & - & - & 2 & - \\
Thyroid cancer & - & - & 1 & 1 \\
Gastric cancer & - & 1 & - & 1 \\
Others & 1 & 5 & 1 & - \\
\hline
\end{tabular}

after various periods of time. The average time for this delay was 4 days (range 1-16 days). In patients treated in the oncology clinics, the onset of sensory impairments and minor pareses was not established in the medical treatment records. Only 11 out of 84 patients with neurological deficits were directly referred to the emergency department in our hospital. Those were the patients who live in our city, who had previously undergone oncological treatment in our hospital. The remaining 73 patients were primarily hospitalized at neurological, internal medicine, oncology, hematology and orthopedic wards, or diagnosed at the emergency departments of other hospitals. Table 4 shows the number of patients hospitalized at different wards, the median hospitalization time, diagnostic investigations and the time from radiological examinations to their results.

Prior to being referred to the oncology center, the patients were treated symptomatically. 37 patients received analgesics drugs and steroid hormones (Dexaven). In 27 patients orthopedics corsets were recommended. Antithrombotic prevention was introduced in 32 patients.

The date of spinal radiotherapy was determined by the "onco-team" with the participation of the orthopedic surgeon, oncologist and radiation therapist. The average waiting time for CT results was 2.4 days, and 2.8 days for MRI results. The mean time between patients' admission to the hospital and orthopedic consultation in the oncology center was 4.5 days (this data does not include the patients diagnosed and examined at the emergency department who were admitted to the hospital on the same day).

\section{Discussion}

Symptoms of neurological deterioration in conjunction with spinal diseases are a common indication for urgent surgical intervention. Treatment outcomes are determined by the mechanism of injury and the extent of the nerve structures damaged. These patients should be urgently 
Table 4 Data concerning the diagnostics of 73 patients with neurological symptoms in the course of metastatic disease of the spine, before consultation in our department

\begin{tabular}{|c|c|c|c|c|c|c|}
\hline Hospital wards & $\begin{array}{l}\text { Number of } \\
\text { patients }\end{array}$ & $\begin{array}{l}\text { Mean hospitalizationtime } \\
\text { (days) }\end{array}$ & $\begin{array}{l}\text { Number of performed } \\
\text { CT examinations }\end{array}$ & $\begin{array}{l}\text { Number of performed } \\
\text { MRI examinations }\end{array}$ & $\begin{array}{l}\text { Mean wait time for } \\
\text { CT results (days) }\end{array}$ & $\begin{array}{l}\text { Mean wait time for } \\
\text { MRI results (days) }\end{array}$ \\
\hline Internal medicine & 9 & 4,4 & 6 & 5 & 2,7 & 3,3 \\
\hline Neurological & 22 & 7,8 & 14 & 13 & 3,7 & 4,2 \\
\hline Oncology & 4 & 4,5 & 1 & 1 & 2 & 3 \\
\hline Hematology & 3 & 4,3 & 1 & - & 3 & - \\
\hline Radiotherapy & 2 & 3,5 & 1 & - & 2 & - \\
\hline Surgery & 2 & 3,5 & 2 & - & 2 & - \\
\hline Rehabilitation & 1 & 5 & 1 & - & 3 & - \\
\hline Orthopedic & 11 & 2,7 & 11 & 7 & 1 & 1 \\
\hline $\begin{array}{l}\text { Emergency } \\
\text { Department }\end{array}$ & 19 & - & 19 & 5 & - & - \\
\hline
\end{tabular}

admitted to special hospital wards, and have the necessary diagnostic evaluations for adequate treatment.

In oncologic patients neurological symptoms worsen over a long period of time. Knowledge of spinal metastases symptoms, by the patients, their families and doctors, often plays a crucial role in early diagnosis and the reduction in the risk of complications $[1,8,9]$.

The study has confirmed the observations of other authors who concluded that most patients present prodromal signs of deep neurological dysfunction such as: changes in the intensity and type of pain, numbness, tingling in the limbs, general weakness and reduced mobility $[1,2,10-13]$.

Spinazze indicated that $5-14 \%$ of patients with metastases of the spine presented symptoms of nervous structure damage. $96 \%$ of the patients reported increased pain during coughing and defecating. The most commonly reported symptoms of spinal cord compression were: dysesthesia $(51-80 \%$ of the patients), decreased muscle strength and feelings of weakness (40-64\%), urethral sphincter dysfunction (40-64\%) [14].

Early and proper diagnosis is one of the factors which plays a crucial role in determining treatment outcome/s. Despite the availability of MRI and CT, there are still many cases of deep, inveterate damage to the nervous system, in the course of undiagnosed or inadequately treated metastatic disease of the spine. The ESCC (Epidural Spinal Cord Compression) scale differentiates between four grades of spinal cord compression, through tumor. Grade 0 means bone-only location of tumor and, due to a risk of neurological deficits, does not require urgent surgical intervention. Grades 1,2,3 represent compression of structures such as dura mater, spinal cord, and the obstruction of CSF flow. Such images are indications for urgent consultation in a spinal surgery centre. As is commonly known, enhanced treatment outcomes are achieved in patients with minimally intense and short-term dysfunctions. These patients are much more likely to rapidly regain their physical functions $[1,2,15,16]$.

Schoeggl et al. found that $25 \%$ of patients with neurological deficits, during the course of metastatic disease of the spine, improved neurologically after adequate treatment. There was no postoperative improvement in patients with complete limb paralyses. The best outcomes were reported in patients with minor pareses (68\% of cases improved). Impaired sphincter function was positively affected in $18 \%$ of patients. The authors highlighted the need for early diagnostics and urgent surgical intervention as the two most crucial factors in determining the outcome [17].

Wals, Gokashlan et al. reported decreased pain in 76$100 \%$ of surgically treated patients, and neurological improvement in $50-76 \%$ of cases. The authors observed significantly improved outcomes in patients with less severe neurological deficits, $81-95 \%$ of whom improved $[18,19]$.

Finkelstain proved that the risk of death is $19 \%$ higher in patients with neurological complications, than in patients with no deficits. He concluded that the occurrence of neurological deficits is one of the most significant negative prognostic factors [8].

An overestimation of the effectiveness of radiotherapy may be one of the reasons for delayed treatment. Neither oncologists, nor palliative care physicians, neurologists and internists cooperate with orthopedic or neurosurgery specialists once spinal metastasis is diagnosed, but refer the patients to radiotherapy clinics or wards [2].

Patchell reported that $85 \%$ of patients after surgical treatment and $57 \%$ of patients who had undergone radiotherapy treatment for spinal metastases, regained their ability to work. $62 \%$ of patients who underwent surgical intervention, regained their ability to walk. This is in contrast with only $19 \%$ of patients treated with radiotherapy [20]. 
A common assumption still exists that there are no indications for spinal surgery in oncology patients due to their expectedly short survival.

The median survival times of patients with spinal metastases, reported by Tokuhashi, were: thyroid cancer- 25.6 months, breast cancer- 18.6 months, prostate cancer- 17.9 months, kidney cancer- 9.8 months, lung cancer- 5.2 months [21].

Bilski proved that surgical treatment prolongs survival in patients with metastases to the spine. The patients remain under outpatient care, their condition and quality of life are better $[4,5]$.

Studies by Kwok revealed that $30 \%$ of patients live longer than a year despite pareses or paralyses of limbs in the course of metastatic disease of the spine [22].

It is now believed that all patients should be qualified for surgical treatment if their survival prognosis exceeds 3 months and their general condition allows it. Among many scales introduced to facilitate qualification, the systems by Tomita, Tokuhashi, Asdourian, Karnofsky, and Harrington are most frequently used. It is essential that the qualification is multidisciplinary and multifactorial $[1,2,23]$.

Our study clearly suggests that both patients and healthcare practitioners ultimately bear the responsibility for delays in adequate surgical treatment. New, significant signs of the disease are either ignored or suppressed by patients. This lack of reaction is often the result of insufficient knowledge of the disease and its related hazards. Nurses and doctors still have insufficient knowledge concerning spinal metastases symptoms. A common assumption is that the effective treatment of spine metastases is impossible, thus delaying proper radiological examination, which can lead to a worsening in prognosis.

\section{Conclusions}

The lack of patient knowledge, regarding the need for diagnostics, as soon as neurological symptoms occur, is the main reason for delayed surgical treatment. Diagnostics of oncology patients is not conducted at competent wards and lasts far too long, reducing the patient's chances for effective treatment. Education of patients and healthcare practitioners dealing with cancer can significantly facilitate early and adequate diagnostics, and thus improve outcomes.

\section{Abbreviations}

CSF: Cerebrospinal fluid; CT: Computed tomography; ESCC: Epidural Spinal Cord Compression; MRI: Magnetic resonance imaging

\section{Acknowledgements}

Not applicable.

Funding

No fundings.

\section{Availability of data and materials}

The datasets generated and/or analyzed during this study are not publicly available, due to the fact that they are paper documents, written in Polish, and are stored in the hospital's archives. Documents are available from the corresponding author upon reasonable request.

\section{Authors' contributions}

GG is a sole author of the manuscript (conception, design, acquisition of data, analysis and interpretation of data and statistic analysis). The author read and approved the final manuscript.

\section{Authors information}

Grzegorz Guzik PhD is the chief of the Oncological Orthopedics Department in the Podkarpackie Oncologcal Center in Brzozów, Poland. Grzegorz Guzik is the author of over 40 papers and one book in the field of oncology.

\section{Ethics approval and consent to participate}

The research was conducted in accordance with the declaration of Helsinki. As this retrospective analysis consists of anonymous clinical data, the Research Ethics Committee deems the application for and the issue of Ethics approval unnecessary.

All the personal data was removed before the author began his research (had access to the data).

All patients signed a written consent form, for the use of their data for this research.

Name of Ethics Committee.

"District Medical Chamber in Krakow Ethics Committee".

\section{Consent for publication}

Manuscript does not contain any individual person's data.

\section{Competing interests}

The authors declare that they have no competing interests.

\section{Publisher's Note}

Springer Nature remains neutral with regard to jurisdictional claims in published maps and institutional affiliations.

Received: 22 March 2017 Accepted: 27 February 2018

Published online: 07 March 2018

\section{References}

1. Guzik G. Przerzuty do kręgosłupa - diagnostyka i leczenie. Bielsko Biała: Alfa-medica press; 2015.

2. Dickman CA, Fehlings MG, Gokaslan ZL. Spinal cord and spinal column tumors principles and Practise. New York: Thieme; 2006.

3. Ecker RT, et al. Diagnosis and treatment of vertebral column metastases. Mayo Clinic Proc. 2005;80(9):1177-86.

4. Bilsky MH, Lis E, Raizer J, Lee H, Boland P. The diagnosis and treatment of metastatic spinal tumor. The Oncolog. 1999;4:459-69.

5. Bilsky M, Smith M. Surgical approach to epidural spinal compression. Hematol Oncol Clin N Am. 2006;20:1307-17.

6. Gilbert RW, Kim JH, Posner JB. Epidural spinal cord compression from metastatic tumor: diagnosis and treatment. Ann Neurol. 1978;3:40-51.

7. Anderson M, Tummala S. Herpes myelitis after thoracic spine surgery. J Neurosurg Spine. 2013;18(5):519-23.

8. Finkelstein JA, Zaveri G, Wai E, Vidmar M, Kreder H, Chow E. A population based study of surgery for spinal metastases - survival rates and complications. J Bone Joint Surg. 2003;85-B(7):1045-50.

9. Kim DH, Chang UK, Kim SH, Bilsky MH. Tumors of the spine. Philadelphia: Saunders Elsevier; 2008.

10. Galasko CSB, Norris HE, Crank S. Spinal instability secondary to metastatic cancer. J Bone Joint Surg. 2000;82A:570-6.

11. Rose $S P$, et al. Metastatic disease in the thoracic and lumbar spine: evaluation and management. J Am Acad Orthop Surg. 2011;19:37-48.

12. Schalberg J, Gainor BJ. A profile of metastatic carcinoma of the spine. Spine. 1985:58:2589-93.

13. Weigel B, Maghsudi M, Neumann C, Kretschmer R, Muller FJ, Nerlich M. Surgical management of symptomatic spinal metastases. Postoperative outcome and quality of life. Spine. 1999;21:2240-6. 
14. Spinazze S, Caraceni A, Schrjivers D. Epidural spinal cord compression. Crit Rew Oncol Hematol. 2005;56:397-406.

15. Harrigton KD. Metastatic disease of the spine. J Bone Joint Surg. 1986;68(A): $1110-5$.

16. Rodallec MH, Feydy A, Larousserie F, Anract P, Campagna R, Babinet A, Zins M, Drapé JL. Diagnostic imaging of solitary tumors of the spine: what to do and say. Radiographics. 2008;28:1019-41.

17. Schoeggl A, Reddy M, Matula C. Neurological outcome following laminectomy in spinal metastases. Spinal Cord. 2002;40:363-6.

18. Walsh GL, Gokaslan ZL, McCutcheon IE, et al. Anterior approaches to the thoracic spine in patients with cancer: indications and results. Ann Thorac Surg. 1997;64:1611-8.

19. Gokaslan ZL, York JE, et al. Transthoracic vertebrectomy for metastatic spinal tumors. J Neurosurg. 1998;89:599-609.

20. Patchell RA, Tibbs PA, Regine WF, Payne R, Saris S, Kryscio R, et al. Direct decompressive surgical resection in the treatement of spinal cord compression caused by metastatic cancer. Lancet. 2005:366:643-8

21. Tokuhashi Y, Oda H, Oshima M. A revised scoring system for preoparative evaluation of metastatic spine tumor prognosis. Spine. 2005;30:2186-91.

22. Kwok Y, DeYoung C, Garofalo M, Dhople A, Regine W. Radiation oncology emergencies. Haem Oncol Clin N Am. 2006;20:505-22.

23. Guzik G. Surgical treatment in patients with spinal tumors - differences in surgical strategies and malignancy-associated problems. An analysis of 474 patients. Ortop Traumatol Rehabil. 2015;17(3):229-40.

\section{Submit your next manuscript to BioMed Central} and we will help you at every step:

- We accept pre-submission inquiries

- Our selector tool helps you to find the most relevant journal

- We provide round the clock customer support

- Convenient online submission

- Thorough peer review

- Inclusion in PubMed and all major indexing services

- Maximum visibility for your research

Submit your manuscript at www.biomedcentral.com/submit 